\title{
Avaliação sob medida para governar o processo de alfabetização
}

\section{Renata Sperrhake}

\begin{abstract}
MELLO, Darlize Teixeira de. Provinha Brasil (ou "Provinha de Leitura"?): mais uma "avaliação sob medida" no processo de alfabetização e "letramento inicial"? 2012. 432 f. Tese (Doutorado em Educação) - Faculdade de Educação, Universidade Federal do Rio Grande do Sul, Porto Alegre, 2012.
\end{abstract}

Atualmente temos, na produção acadêmico-científica, ao menos duas vertentes ou perspectivas de trabalho envolvendo dados estatísticos: uma é a que se utiliza do ferramental estatístico para produzir dados e análises, ou seja, aqueles estudos e pesquisas que, por meio de métodos variados, buscam compreender dinâmicas de diferentes fenômenos através dos números e do que eles são capazes de dizer. Em geral, nessa vertente encontramos estudos que abordam as chamadas estatística descritiva e estatística inferencial ou probabilística. Encontramos essa perspectiva em diversas áreas, tais como na área das ciências biológicas e da saúde, das engenharias, em alguns estudos da psicologia e das ciências humanas, sociais e aplicadas.

A outra vertente, bem mais frequente em estudos das áreas da filosofia, da sociologia, da epistemologia das ciências e, mais recentemente, também da educação, busca problematizar - e aqui utilizo esse termo baseando-me nos estudos de Michel Foucault ${ }^{1}$ - os usos e os efeitos da produção discursiva envolvendo dados numéricos e estatísticos. Alguns autores se destacam nessa perspectiva, como Ian Hacking, Thomas S. Popkewitz, Alain Desrosiéres e, no Brasil, Nelson Senra, apenas para citar alguns. Tais problematizações buscam analisar como a produção discursiva numérica produz formas de se conduzir e, portanto, produzir sujeitos, funcionando tanto em âmbito governamental ou coletivo quanto em âmbito individual.

\footnotetext{
${ }^{1}$ Segundo Foucault, problematização seria um "conjunto de práticas discursivas e não discursivas que faz alguma coisa entrar no jogo do verdadeiro e do falso e o constitui como objeto para o pensamento" (Foucault, 2006, p. 242).
} 
Darlize Teixeira de Mello, em sua tese de doutorado intitulada Provinha Brasil (ou "Provinha de Leitura"?): mais uma "avaliação sob medida" no processo de alfabetização e "letramento inicial"?, defendida no Programa de Pós-Graduação em Educação da Universidade Federal do Rio Grande do Sul (UFRGS), sob orientação da professora doutora Iole Maria Faviero Trindade, e publicada em 2012, trabalha com essas duas perspectivas ao estudar e analisar diferentes formas de avaliação da alfabetização de crianças. A autora objetiva:

[...] examinar os discursos estatísticos e pedagógicos contemporâneos relativos à avaliação destinada às classes de alfabetização, marcados metodologicamente por orientações diversas e hegemônicas em tempos e espaços diversos, acompanhando, assim, a trajetória da escolarização e da alfabetização em massa no Brasil do século XX, para, na contemporaneidade do século XXI, analisar a forma como a avaliação governa a escolarização da alfabetização no nosso país. (Mello, 2012, p. 22).

Para tanto, vale-se de um amplo e diversificado material empírico e, como é típico de análises em pesquisas pós-críticas, mescla estratégias metodológicas e analíticas para concretizar seu estudo.

Com amparo teórico nos estudos foucaultianos, a avaliação educacional é tomada pela autora como uma técnica de governamento, ${ }^{2}$ ou seja, como uma forma de regulação e normalização das condutas das pessoas no âmbito daquilo que Foucault chamou de "governamentalidade". Com essa lente, são analisadas três formas de avaliação da alfabetização: os Testes ABC, os testes psicogenéticos de leitura e escrita e a Provinha Brasil. A autora mostra e argumenta que essas três avaliações ganham hegemonia em diferentes épocas, sendo regidas por discursos pedagógicos que pretendem produzir uma "alfabetização sob medida".

A tese se organiza e conduz o leitor com um zoom no objeto de análise ao longo dos seus seis capítulos, desde a avaliação educacional da alfabetização, com uma leitura desta como tecnologia de governamento das populações escolares e produção do sujeito aluno, até os resultados da Provinha Brasil na rede municipal de ensino de Porto Alegre, no período de 2008 a 2010, com uma leitura das formas de condução das condutas baseada na produção numérica envolvendo os resultados.

Por meio de um percurso histórico das práticas escolares de exame, buscando os pontos de emergência de alguns dos discursos pedagógicos sobre avaliação da alfabetização, a autora argumenta que a ação de avaliar se torna um ritual disciplinador de sujeitos e de saberes, tanto no interior da escola quanto em termos de políticas educacionais. Para estas últimas, as estatísticas produzidas pelas avaliações externas pretendem mapear zonas e populações consideradas de risco, de modo a intervir e minimizar esse risco.

E seria possível medir, com certeza e precisão, a aprendizagem da leitura e da escrita? Seria possível quantificar as habilidades envolvidas nos processos de ler e escrever? Tendo o discurso da pedagogia científica experimental como ponto de proveniência, Mello (2012) discute como a educação brasileira apresenta algumas

\footnotetext{
${ }^{2}$ Veiga-Neto (2002) propõe a utilização de governamento, diferenciando-a de governo. Aqui também assumirei tal distinção.
} 
tentativas de realização dessa mensuração das habilidades envolvidas na leitura e na escrita. Os Testes ABC, de Lourenço Filho, utilizados no Brasil no período de 1930 a 1970, são tomados como marco referencial dessas tentativas. Tais testes buscavam classificar estudantes em relação à sua maturação para a aprendizagem da leitura e da escrita e tinham como objetivo organizar classes homogêneas de alunos, separando-os hierarquicamente com a finalidade de alcançar maior eficiência na ação de alfabetizar. Já os testes psicogenéticos de escrita, criados por Emília Ferreiro e Ana Teberosky na década de 1980, buscavam compreender o processo de aprendizagem da criança mediante níveis de conceitualização e desenvolvimento. O último teste analisado pela autora é a Provinha Brasil: caracterizada como uma ação governamental, tal avaliação, formulada a partir de uma matriz de referência, busca medir as habilidades relativas à alfabetização e ao letramento dos estudantes.

Ainda que toda a tese seja de grande fôlego, trazendo contribuições de diversos autores e fazendo a operação foucaultiana de buscar pela emergência das avaliações da alfabetização, o que demanda estudo de amplo e diversificado material teórico e de análise, é na Provinha Brasil que Mello (2012) concentra sua investigação. Destacase a originalidade das análises do Capítulo 4, que focaliza a aproximação entre as habilidades descritas na Matriz de Referência da Provinha Brasil de 2008 e os discursos das definições presentes nas políticas públicas e nos estudos acadêmicos da área da alfabetização, do letramento e do analfabetismo. Nesse capítulo, a autora se debruça também sobre as questões presentes no instrumento de avaliação da Provinha Brasil, na sua forma de correção e nas habilidades esperadas - chamadas de descritores na Matriz de Referência - dos estudantes em cada um dos eixos avaliados e em cada um dos níveis das escalas de proficiência. ${ }^{3}$ Outro movimento analítico realizado é a comparação das diferentes edições da Provinha Brasil, o que permite que a autora mostre quais habilidades ganham visibilidade em cada edição e em cada nível da escala de proficiência proposta pela prova.

Ao lançar o olhar para os resultados da Rede Municipal de Ensino de Porto Alegre, no período de 2008 a 2010, nas duas edições anuais da Provinha Brasil, a autora busca pelas questões com maior e menor percentual de acerto pelos estudantes. Desse modo, são analisadas 62 questões, entre as mais acertadas e as mais erradas pelos alunos, nas duas provas das três edições de aplicação da Provinha Brasil. É nesse momento que vemos com maior evidência a presença dos dois tipos de análise envolvendo estatísticas educacionais, mencionados no início desta resenha. Mello (2012) utiliza ferramentas e métodos estatísticos para analisar os dados da Rede Municipal de Ensino de Porto Alegre e, também, problematiza esses dados e a produção discursiva deles decorrente. Ou seja: a problematização focaliza não apenas os dados em si, mas também os discursos educacionais e sobre a alfabetização que são ensejados a partir deles. Nesse sentido, as conclusões a que a autora chega apontam que a Provinha Brasil tem sua ênfase na avaliação de habilidades de leitura,

\footnotetext{
${ }^{3}$ Escala de proficiência é a forma como alguns dos resultados da maioria das avaliações em larga escala são organizados. Ela é uma espécie de régua onde são posicionados os alunos com base em seu desempenho na avaliação. A escala de proficiência é composta por níveis nos quais estão alocadas as habilidades avaliadas nos diferentes itens (ou questões) da prova.
} 
pois nos testes 1 e 2, no período de 2008 a 2011, "68 questões formam o eixo apropriação do sistema de escrita, enquanto 126 compuseram o eixo leitura"(Melo, 2012, p. 176).

Outra consideração feita pela autora é que, na rede municipal analisada, os estudantes tiveram mais acertos nas questões que envolviam habilidades de apropriação do sistema de escrita, ou seja, naquelas com foco no "reconhecimento de letras, sílabas e na leitura de palavras formadas por sílabas canônicas e não canônicas, como também, mas com menos ênfase, na finalidade do texto" (Mello, 2012, p. 378). Esse dado leva a autora a argumentar que a Provinha Brasil favorece uma "visibilidade da alfabetização" e uma "invisibilidade do letramento". O argumento para sustentar esta última afirmação se centra em dois aspectos:

1) o menor percentual de acerto das questões que avaliam "para que servem textos do uso cotidiano, assim como do que tratam, como se organizam suas narrativas em termos de tempo, espaço e com que personagens ou, ainda, o que dá para inferir de informações" (Mello, 2012, p. 378), ou seja, as habilidades voltadas ao letramento;

2) o baixo percentual não seria decorrente de os alfabetizandos terem ou não desenvolvido tais habilidades, mas sim do modo como a avaliação foi formulada, do que e como ela avalia. Nesse sentido, a autora argumenta que a invisibilidade do letramento também é sustentada pela necessidade de uma fluência em leitura autônoma, ainda não obtida pelos alfabetizandos, que é fundamental para a realização da prova e a compreensão das questões. Assim, seria esse um impedimento da avaliação do "letramento inicial", o que o invisibilizaria na tentativa de mensuração produzida pela prova.

É esse argumento que faz a autora questionar, já no título de seu trabalho, a expressão "letramento inicial", visto que, segundo sua análise, esse letramento não estaria sendo medido adequadamente, pelas razões já expostas.

Pelos elementos levantados até aqui, julgo ser inegável a contribuição da referida tese para as áreas da avaliação e da alfabetização. A análise minuciosa de amplo e diversificado material da Provinha Brasil, abrangendo matrizes de referência, cadernos de provas, guias de aplicação, correção e interpretação dos resultados, assim como os resultados de três edições de uma rede pública de ensino, mostra a potencialidade tanto da abordagem teórico-metodológica utilizada quanto do tema da pesquisa.

A produção discursiva a respeito das avaliações externas e dos seus resultados tem proliferado nos últimos anos, não apenas em nível político, acadêmico e científico, mas também em nível midiático. Estudos e análises que buscam compreender os meandros e os diferentes vieses dessas avaliações, para além dos percentuais expostos em jornais de grande circulação, colaboram para a compreensão da complexidade envolvida tanto na concepção, criação e aplicação de avaliações desse tipo, quanto na complexidade do fenômeno a ser avaliado, neste caso, a alfabetização e suas diferentes facetas. 
FOUCAULT, M. O cuidado com a verdade. In: FOUCAULT, M. Ética, sexualidade e política. 2. ed. Rio de Janeiro: Forense Universitária, 2006. p. 240-251. (Ditos e Escritos, 5).

VEIGA-NETO, A. Coisas de governo... In: RAGO, M.; ORLANDI, L. B. L.; VEIGANETO, A. (Org.). Imagens de Foucault e Deleuze: ressonâncias nietzschianas. Rio de Janeiro: DP\&A, 2002. p. 13-34.

Renata Sperrhake, doutora em Educação pela Universidade Federal do Rio Grande do Sul (UFRGS), atua na área de Formação Pedagógica e Linguagem como docente do Curso de Pedagogia da Faculdade de Educação. É integrante do Grupo de Pesquisa sobre Educação e Disciplinamento (GPED).

renata.sperrhake@gmail.com

Recebido em 23 de março de 2020

Aprovado em 25 de maio de 2020 